\title{
The Biostatistics of Aging. From Gompertzian Mortality to an Index of Aging-Relatedness
}

Description: A practical and clarifying approach to aging and aging-related diseases

Providing a thorough and extensive theoretical framework, The Biostatistics of Aging: From Gompertzian Mortality to an Index of Aging-Relatedness addresses the surprisingly subtle notion with consequential biomedical and public health relevance of what it means for a condition to be related to aging. In this pursuit, the book presents a new quantitative method to examine the relative contributions of genetic and environmental factors to mortality and disease incidence in a population.

With input from evolutionary biology, population genetics, demography, and epidemiology, this medically motivated book describes an index of aging-relatedness and also features:

- Original results on the asymptotic behavior of the minimum of time-to-event random variables, which extends those of the classical statistical theory of extreme values

- A comprehensive and satisfactory explanation based on biological principles of the Gompertz pattern of mortality in human populations

- The development of an evolution-based model of causation relevant to mortality and aging-related diseases of complex etiology

- An explanation of how and why the description of human mortality by the Gompertz distribution can be improved upon from first principles

- The amply illustrated analysis of real-world data, including a program for conducting the analysis written in the freely available R statistical software

- Technical appendices including mathematical material as well as an extensive and multidisciplinary

bibliography on aging and aging-related diseases

The Biostatistics of Aging: From Gompertzian Mortality to an Index of Aging-Relatedness is an excellent resource for practitioners and researchers with an interest in aging and aging-related diseases from the fields of medicine, biology, gerontology, biostatistics, epidemiology, demography, and public health.

Contents:

PREFACE AND ACKNOWLEDGMENT ix

1 Introduction 1

2 An Account of Gompertzian Mortality through Statistical and Evolutionary Arguments 6

2.1 The Statistical Theory of Extreme Values 10

2.2 The Evolutionary Theory of Aging 36

3 The Argument against Gompertzian Mortality 69

3.1 Departures from the Gompertz Model 70

3.2 An Evolution-Based Model of Causation 72

4 The Index of Aging-Relatedness 93

4.1 A Survival Mixture Model of the Gompertz and Weibull Distributions 94

4.2 Definition and Interpretation of the Index of Aging-Relatedness 97

4.3 The Survival Mixture Model and Competing Risks 103

4.4 Estimation of the Model Parameters 107 
4.5 Illustrative Application: The Israeli Ischemic Heart Disease Study 109

4.6 Precision of Estimation 122

5 Discussion: Implications 128

5.1 The Meaning of the Gompertz Parameter 128

5.2 Age as a Risk Factor for Disease 132

5.3 Are Aging-Related Diseases an Integral Part of Aging? 134

5.4 Biological versus Chronological Aging 135

5.5 The Public Health Notion of Compression of Morbidity 138

5.6 A Picture of Aging for the Twenty-First Century 143

APPENDIX A: PROOFS OF RESULTS IN SECTION 2.1.2 WITH SOME EXTENSIONS 154

APPENDIX B: DERIVATION OF HAMILTON S EQUATION FOR THE FORCE OF NATURAL SELECTION ON MORTALITY 170

APPENDIX C: SOME PROPERTIES OF THE GOMPERTZ AND WEIBULL DISTRIBUTIONS 174

APPENDIX D: FIRST AND SECOND PARTIAL DERIVATIVES OF THE MIXTURE LOG-LIKELIHOOD FUNCTION 178

APPENDIX E: EXPECTATION CONDITIONAL MAXIMIZATION (ECM) ALGORITHM 183

APPENDIX F: R PROGRAM 190

REFERENCES 226

AUTHOR INDEX 245

SUBJECT INDEX 253

Ordering: $\quad$ Order Online - http://www.researchandmarkets.com/reports/2586707/

Order by Fax - using the form below

Order by Post - print the order form below and send to

Research and Markets,

Guinness Centre,

Taylors Lane,

Dublin 8,

Ireland. 


\section{RESEARCHANDMARKETS Page 1 of 2}

\section{Fax Order Form}

To place an order via fax simply print this form, fill in the information below and fax the completed form to 646-607-1907 (from USA) or +353-1-481-1716 (from Rest of World). If you have any questions please visit

http://www.researchandmarkets.com/contact/

\section{Order Information}

Please verify that the product information is correct.

$\begin{array}{ll}\text { Product Name: } & \text { The Biostatistics of Aging. From Gompertzian Mortality to an Index of } \\ & \text { Aging-Relatedness } \\ \text { Web Address: } & \text { http://www.researchandmarkets.com/reports/2586707/ } \\ \text { Office Code: } & \text { SC }\end{array}$

\section{Product Format}

Please select the product format and quantity you require:

\section{Quantity}

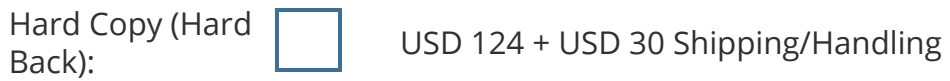

* Shipping/Handling is only charged once per order.

* The price quoted above is only valid for 30 days. Please submit your order within that time frame to avail of this price as all prices are subject to change.

\section{Contact Information}

Please enter all the information below in BLOCK CAPITALS

Title:

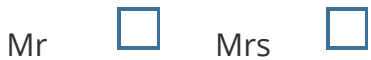

$\mathrm{Dr}$

Miss

$\square$ Ms

Prof

First Name:

Last Name:

Email Address: *

Job Title:

Organisation:

Address:

City:

Postal / Zip Code:

Country:

Phone Number:

Fax Number:

* Please refrain from using free email accounts when ordering (e.g. Yahoo, Hotmail, AOL) 


\section{RESEARCHANDMARKETS Page 2 of 2}

\section{Payment Information}

Please indicate the payment method you would like to use by selecting the appropriate box.

Pay by credit card:

Pay by check:
You will receive an email with a link to a secure webpage to enter your credit card details.

Please post the check, accompanied by this form, to:

Research and Markets,

Guinness Center,

Taylors Lane,

Dublin 8,

Ireland.

Bank details will be provided on the invoice which you will receive after you place your order with us.

Pay by Wire Transfer:

If you have a Marketing Code please enter it below:

Marketing Code:

Please note that by ordering from Research and Markets you are agreeing to our Terms and Conditions at http://www.researchandmarkets.com/info/terms.asp

Please fax this form to:

(646) 607-1907 or (646) 964-6609 - From USA

+353-1-481-1716 or +353-1-653-1571 - From Rest of World 